\title{
Effects of Post-Joint Comprehensive Plan of Action Sanctions on the Nutritional Status and Food Security of Pregnant Women and Their Families (2017-2020)
}

\section{Morteza Gohari}

Mashhad University of Medical Sciences

Maryam Khosravi ( $\sim$ khosravim@mums.ac.ir)

Mashhad University of Medical Sciences

Jamshid Jamali

Mashhad University of Medical Sciences

Majid Khadem-Rezaiyan

Mashhad University of Medical Sciences

Golnaz Ranjbar

Mashhad University of Medical Sciences

Fatemeh Khorramrouz

Mashhad University of Medical Sciences

\section{Research Article}

Keywords: Sanctions, JCPOA, Food Security, Pregnancy, Birth Weight, Generalized Estimation Equations (GEEs)

Posted Date: January 31st, 2022

DOI: https://doi.org/10.21203/rs.3.rs-1187448/v1

License: (c) (i) This work is licensed under a Creative Commons Attribution 4.0 International License. Read Full License 


\section{Abstract}

Background \& Objective: Sanctions against a country could be a shock to the country's economy for a specific period. Iran has been subject to various sanctions for the past 40 years, and these sanctions have been intensified since 2011. Unprecedented sanctions were imposed on Iranians after the United States withdrew from the Joint Comprehensive Plan of Action (JCPOA) agreement, and a disastrous economic situation is the outcome of this international issue. The present study aimed to evaluate the impact of this situation on the nutritional status and food security of pregnant women and their families.

Materials and Methods: Data were collected using questionnaires of SINA electronic health record system (SINAEHR®) for 19 comprehensive health centers in Razavi Khorasan province, Iran. Data were collected using the census method, and 266,182 pregnant women were investigated. Data analysis was performed using Generalized Estimation Equations (GEE).

Results: Weight gain during pregnancy $(P<0.001)$ and birth weight of the newborns $(P<0.047)$ significantly decreased during the sanctions.

Conclusion: According to the results, there has been a significant reduction in the two variables of weight gain in pregnant women and newborns birth weight, which confirms the debilitative effects of sanctions on the nutritional status and health of pregnant women and infants in Iran.

\section{Background}

In recent decades, Iran has experienced various sanctions imposed by the United States and Europe. Unfortunately, anti-Iranian sanctions intensified since 2011, and the peak of these sanctions began on November 4, 2016 by the United States (1). With the beginning of post-JCPOA sanctions, extreme changes affected economic indicators such as the inflation index, consumer price index, and food price index in Iran (2) This issue is of paramount importance regarding the nutritional status of high-risk populations, including pregnant women and infants (3-5).

Poor nutrition during pregnancy could lead to short-term and long-term consequences for the mothers and newborns. Such examples are postpartum hemorrhage, prolonged labor, Spontaneous abortion, fetal abnormalities, intrauterine growth restriction, preterm birth, and low birth weight (LBW) (6-8). Infants born under such circumstances will be exposed to diseases such as obesity, type II diabetes, hypertension, and cardiovascular diseases in the future (6).

In a study in this regard, Aloosh et al (9), reported that sanctions adversely affect public health by impeding access to various drugs and treatments. Furthermore, Kokabi (10) stated that sanctions have reduced wellbeing due to impaired access to food and medicine. In another study, Danaei et al (11), observed unfavorable access to medicine and medical services due to post-JCPOA sanctions. Notably, the sample population and outcomes of the aforementioned studies are different. 
The present study aimed to investigate the effects of post-JCPOA sanctions on the nutritional status of pregnant women and infants and evaluate the food security status in the households of pregnant women.

\section{Methods}

\section{Data Sources}

SINA electronic health record system (SinaEHR®) is an integrated health information system supervised by Mashhad University of Medical Sciences, which contains the health records of more than five million people in Razavi Khorasan province, Iran. The values of the variables that are monitored and measured in the comprehensive health centers of this province ( $98.6 \%$ of the total population) have been recorded in the integrated health information system since 2016. Due to the registration of all services in this system, any dynamic report and access to classified health information of individuals could be obtained.

In this study, we extracted data on sociodemographic and anthropometric measurements, household food security scores, and laboratory outcomes from the system. Data were collected on maternal body mass index (BMI) at the beginning of pregnancy, maternal weight gain during pregnancy, maternal supplementation status, household food security scores, neonatal birth weight, term/pre-term birth status, and maternal hemoglobin concentration.

\section{Study Design}

Initially, data of the pregnant women and infants referring to a comprehensive health center in Razavi Khorasan province were extracted during March 2017-2020 (36 months). Following that, the participants were selected from 19 comprehensive health centers were considered, and the available data in each center were divided on a monthly basis. The obtained data were analyzed using Generalized Estimation Equations (GEEs). Based on timeframe, the data of 19 centers were classified as before the sanctions (from March 21, 2017 to February 19, 2019) and after the sanctions (from February 20, 2019 to March 19, 2020) and analyzed using the GEE statistical model. To divide the timeframe as before and after the sanctions, the headline inflation index and food inflation index were used as recorded in the National Statistics Center of Iran (Figure 1) (2).

\section{Statistical analysis}

After collecting the required data from SINA electronic health record system, data analysis was performed in Excel and then SPSS software using descriptive and analytical statistics. From the line chart simple and dispersion indices (Mean, SD, Median, and Interquartile Range) were used to describe the data and consider the correlation and relationship between variables. In addition, the research hypotheses was tested using GEEs (12). Studies have shown that for the analysis of this type of data, GEEs provide better results compared to other methods $(13,14)$. Data were interpreted at a significance level of $5 \%$.

\section{Results}


We have shown a general description of the population in the tables and figures. Table 1 describes some quantitative and qualitative variables of the population.

Table 1

Descriptive information of the study population

\begin{tabular}{|lllll|}
\hline Variable & \multicolumn{3}{l}{ Median (IQR) } & \multicolumn{2}{l|}{ Mean \pm SD } \\
\cline { 2 - 5 } & $\begin{array}{l}\text { Before } \\
\text { Sanctions }\end{array}$ & $\begin{array}{l}\text { After } \\
\text { Sanctions }\end{array}$ & $\begin{array}{l}\text { Before } \\
\text { Sanctions }\end{array}$ & $\begin{array}{c}\text { After } \\
\text { Sanctions }\end{array}$ \\
\hline $\begin{array}{l}\text { Mothers with appropriate weight } \\
\text { gain (\%) }\end{array}$ & $70(7)$ & $60(8)$ & $64 \pm 7$ & $68 \pm 7$ \\
\hline Birth weight (kg) & $3.18(0.09)$ & $3.17(0.06)$ & $3.18 \pm 0.08$ & $3.17 \pm 0.05$ \\
\hline Mothers taking supplements (\%) & $97(3)$ & $97(2)$ & $96 \pm 2$ & $97 \pm 2$ \\
\hline $\begin{array}{l}\text { Maternal body mass index } \\
\text { (kg/m2) }\end{array}$ & $24.79(1.05)$ & $24.85(0.96)$ & $24.78 \pm 1.03$ & $24.76 \pm 0.7$ \\
\hline Food Security Score * & $1.77(3.25)$ & $1.54(2.74)$ & $2.74 \pm 3.51$ & $2.11 \pm 2.11$ \\
\hline Food pattern rating ** & $9.90(0.55)$ & $9.81(0.54)$ & $9.90 \pm 0.49$ & $9.78 \pm 0.56$ \\
\hline Maternal hemoglobin (g/dl) & $12.78(0.34)$ & $12.75(0.30)$ & $12.78 \pm 0.27$ & $12.79 \pm 0.26$ \\
\hline Gender of boy (\%) & $52(7)$ & $51(5)$ & $52 \pm 8$ & $52 \pm 5$ \\
\hline Non-alcoholics mothers (\%) & $99(0.1)$ & $99(0.1)$ & $99 \pm 0.47$ & $99 \pm 0.40$ \\
\hline Non-smokers mothers (\%) & $99(0.1)$ & $99(0.1)$ & $99 \pm 0.15$ & $99 \pm 0.13$ \\
\hline Maternal anemia (\%) & $0.4(1)$ & $0.1(1)$ & $0.9 \pm 1.6$ & $0.4 \pm 0.7$ \\
\hline Normal delivery (\%) & $60(15)$ & $59(14)$ & $60 \pm 12$ & $60 \pm 10$ \\
\hline Mother's education (years) & $12.8(0.74)$ & $12.6(0.58)$ & $12.8 \pm 0.80$ & $12.5 \pm 0.74$ \\
\hline Employed Mothers (\%) & $16(7)$ & $22(6)$ & $17 \pm 6.7$ & $23 \pm 7.4$ \\
\hline Mother's age (Year) & $29.86(1.22)$ & $28.84(1.13)$ & $29.9 \pm 1.28$ & $29.1 \pm 0.90$ \\
\hline $\begin{array}{l}\text { *Fom O as the safest to 27 as the most insecure score; **from a score of } 0 \text { as the worst food pattern } \\
\text { to a score of 12 as the best food pattern }\end{array}$ & & & \\
\hline
\end{tabular}

Figure 2 depicts the trend the percentage of the mothers with appropriate weight gain during 36 months during three years. A decreasing trend could be observed since April 2019. At the beginning of 2019, $70 \%$ of the mothers had proper weight gain, while only $60 \%$ had proper weight gain at the end of 2019 $(\mathrm{P}<0.001)$.

Figure 3 , shows the trend of changes in the birth weight of infants during 36 months. A decreasing trend could be observed with a very slow slope is seen, while the changes in the mean weight of the infants 
was 100 grams (range: $3.14-3.24 \mathrm{~kg}$ ) over three years, with a relatively small range of change.

The variables of maternal weight gain, birth weight, and maternal supplementation use had significant differences before and after the sanctions $(P \leq 0.001, P=0.047$, and $P=0.006$, respectively). The odds ratio (OR) of these variables was estimated at $0.955,0.985$, and 1.005 , respectively (Table 2 ).

Table 2

Results of Data Analysis Using GEE Model

\begin{tabular}{|c|c|c|c|c|}
\hline Dependent variable & SE & B & OR & P-Value* \\
\hline Maternal weight gain ${ }^{1}$ & 0.0100 & -0.044 & $0.955(0.935-0.976)$ & $<0.001$ \\
\hline Birth weight ${ }^{1}$ & 0.0077 & -0.015 & 0.985(0.969-0.999) & 0.047 \\
\hline Maternal supplementation ${ }^{3}$ & 0.0020 & 0.005 & $1.005(1.002-1.009)$ & 0.006 \\
\hline Maternal diet score & 0.1009 & -0.089 & $0.907(0.668-1.103)$ & 0.378 \\
\hline food security score & 0.3256 & -0.638 & $0.528(0.279-1.000)$ & 0.072 \\
\hline Preterm birth & 0.0070 & -0.004 & $0.996(0.982-1.010)$ & 0.559 \\
\hline Maternal BMI & 0.1159 & 0.137 & $1.128(0.906-1.305)$ & 0.236 \\
\hline Maternal $\mathrm{Hb}^{\star \star}$ concentration & 0.0336 & 0.038 & $1.038(0.972-1.099)$ & 0.254 \\
\hline \multicolumn{5}{|c|}{$\begin{array}{l}\text { *Significant at } 0.05 \text { level; **hemoglobin; } 1 \text { adjusted effects of maternal underlying diseases, maternal } \\
\text { anemia, stillbirth history, maternal alcohol consumption, maternal smoking habits, maternal drug use } \\
\text { maternal education level, maternal occupation status, and maternal age; 2adjusted effects of } \\
\text { neonatal gender, maternal BMI, number of pregnancies, maternal alcohol consumption, maternal } \\
\text { smoking habits, maternal underlying diseases, maternal anemia, stillbirth history, mode of delivery, } \\
\text { maternal education level, maternal occupation status, maternal age, and maternal drug use; } \\
\text { 3adjusted effects of maternal age, maternal education level, maternal occupation status, and } \\
\text { maternal underlying diseases }\end{array}$} \\
\hline
\end{tabular}

\section{Discussion}

According to the results of the present study, post-JCPOA sanctions have had a negative impact on the nutritional status of pregnant women, and also maternal weight gain and birth weight have significantly decreased in this period. These results were expected due to the extreme changes in economic indicators after the sanctions. Similar studies have also investigated the effects of sanctions on the Iranian population in areas such as public health and welfare of the people $(10,11,15,16)$, and health systems and services (17-19), But to our knowledge, no study has been found that examines the negative effects of sanctions on pregnant mothers and fetal development.

Our findings indicated a downward trend in the studied variables. At the beginning of $2019,70 \%$ of mothers had proper weight gain, while at the end of 2019 , only $60 \%$ had proper weight gain during pregnancy. The number of pregnant mothers with appropriate maternal weight gain in the post-sanctions 
period has decreased $(\mathrm{OR}=0.955)$. In other words, according to the odds ratio, for every 1,000 mothers, 45 more mothers suffer from inappropriate weight gain compared to the pre-sanctions period.

Also, we found sanctions were associated with the birth weight of the newborns. The weight of newborns, and weight of newborns was significantly lower after sanctions compared to before sanctions.

Furthermore, adversely affected the proper weight gain of newborns. In a comprehensive study in this regard (3), studies conducted in 69 countries regarding sanctions were reviewed, and it was concluded that sanctions lead to neonates with LBW, and these neonates were reported to have developmental disorders and even early death in the future. In the mentioned study, the most significant impact of sanctions was reported on the mothers and infants who were exposed to the first 2 years of the sanction period. Our findings are in line with the study by loana regarding the severity of post-JCPOA sanctions (3).

In the current research, the number of the mother using supplements also had a significant uptrend and increased by five per 1,000 in the post-sanctions period. These changes could be explained by the fact that supplementation has increased over time due to poor nutrition, and pregnant women cannot compensate for their nutritional deficiencies.

Maternal BMI before pregnancy is a key indicator of maternal nutritional status before the onset of pregnancy (20). Some studies have examined the effects of sanctions on anthropometric indices (e.g., $\mathrm{BMI}$, height, weight) in pregnant women, indicating that the BMI of the mothers who were able to reproduce significantly decreased after sanctions, and sanctions adversely affected proper $\mathrm{BMI}(3,5,21$, 22). However, maternal BMI showed no significant difference before and after the sanctions in the present study.

Household Food security index that gotten using HFIAS or household food insecurity access scale (23) was another important variable in our study, which had no significant difference before and after sanctions. This is inconsistent with the previous findings conducted by Heydari and Hejazi $(24,25)$ showing a significant reduction in daily caloric intake and household food security after sanctions. In the current research, the author guess that daily caloric intake and food security would decrease significantly with the prolongation of post-JCPOA sanctions.

The difference between the food security index in the research by Heydari and our study is that Heydari used the FAO food security index (i.e., average household food security index), which is based on the calorie and protein intake of households, and it is usually calculated with the help of food frequency questionnaire data (26). However, we used the food security index of the Health Ministry (HFIAS). Furthermore, the study by Heydari dates back to before the imposition of severe post-JCPOA sanctions, and the food security index has not changed significantly as a result.

In the current research, no significant change was observed in food insecurity since the system provided us with no data on food insecurity before 2017. Another reason was the COVID-19 pandemic from late 2019 and early 2020, so the data of this period could not be used and the study period had to be shortened. If it were possible to use the data, probably we could have observed the spread of food 
insecurity after the post-JCPOA sanctions. In the study of Hejazi food security was estimated by calculating the share of household food expenditure. Costs of following a healthy diet based on the food pyramid were estimated, and the manual of Smith and Subandoro (25) was also employed to classify food insecurity. The author concludes that food insecurity has increased among urban and rural households during the post-JCPOA sanctions period compared to before. The data required to assess food security in the study of Hejazi are the amount of household income and expenditure to provide food for that family, which are completely different from the assessment method of food security in the present study (HFIAS). Notably, studies in this regard are limited, and further investigations are recommended.

One of the main limitations of our study was the prevalence of COVID-19, which made it impossible to enter the data for late 2019 and shortened the period of the study. Another limitation was the lack of division of the sample population into different groups in terms of economic status.

\section{Conclusion}

According to the results, post-JCPOA sanctions have negatively affected the weight gain of pregnant women and neonates birth weight. These damages are likely to have the greatest impact on individuals with a poor socioeconomic status and may predispose Iranians to multiple serious health problems in the near future. Evidence is scarce regarding the impact of sanctions on different aspects of health at various stages of life. Therefore, further investigations are required to ensure that sanctions do not violate fundamental health rights.

\section{List Of Abbreviations}

JCPOA Joint Comprehensive Plan of Action

LBW Low Birth Weight

BMI Body Mass Index

GEEs Generalized Estimation Equations

SE Standard Error

B Beta coefficient

OR Odds Ratio

$P_{\text {value }} \quad$ Probability value

FAO Food and Agriculture Organization

HFIAS Household Food Insecurity Access Scale 


\section{Declarations}

\section{Ethics approval and consent to participate:}

When mothers are visited for first health cares, informed consent was obtained from all of them and/or their legal guardian. They consent that their information is used confidentially and anonymously for studies. So, when the study protocol was approved by the Research Ethics Committee of Mashhad University of Medical Sciences (Code:

IR.MUMS.MEDICAL.REC.1399.108), the information of mothers who wished to use their data for research, were available us. Also, all methods were carried out in accordance with relevant guidelines and regulations.

Consent for publication: The authors would like to advise that all authors listed have contributed to the work and approved the content of the submitted manuscript.

Availability of data and materials: The data that support the findings of this study are available from corresponding author, but restrictions apply to the availability of these data, which were used under license for the current study, and so are not publicly available. However, if corresponding author gives reasonable request, data will be available.

Competing interests: The authors declare that they have no competing interests.

Funding: Vice Chancellor for Research, Mashhad University of Medical Sciences.

\section{Authors' contributions:}

Conceptualization: Morteza Gohari \& Maryam Khosravi

Methodology: Jamshid Jamali \& Majid Khadem-Rezaiyan

Formal analysis and investigation: Maryam Khosravi \& Morteza Gohari \& Jamshid Jamali \& Majid Khadem-Rezaiyan

Writing - original draft preparation: MG \& MK\& Golnaz Ranjbar \& Fatemeh Khorram-rouz

Writing - review and editing: Morteza Gohari \& Maryam Khosravi \& Golnaz Ranjbar \& Fatemeh Khorramrouz

\section{Acknowledgment}

Hereby, we extend our gratitude to the faculty members of the Department of Nutrition and SINA system members for assisting us in this research project.

\section{References}


1. U.S. DEPARTMENT OF THE TREASURY [Available from: https://home.treasury.gov/policyissues/financial-sanctions/sanctions-programs-and-country-information/iran-sanctions. Accessed 3 April 2020

2. National Statistics Center of Iran [Available from: https://www.amar.org.ir. Accessed 17 May 2020

3. Ioana M. The Humanitarian Impact of Economic Sanctions. 2010.

4. Garfield R. The impact of economic embargoes on the health of women and children. J Am Med Womens Assoc (1972). 1997;52(4):181-4, 98.

5. Delpeuch F, Traissac P, Martin-Prevel Y, Massamba JP, Maire B. Economic crisis and malnutrition: socioeconomic determinants of anthropometric status of preschool children and their mothers in an African urban area. Public health nutrition. 2000;3(1):39-47.

6. Simeoni U, Armengaud J-B, Siddeek B, Tolsa J-FJN. Perinatal origins of adult disease. 2018;113(4):393-9.

7. Bloomfield FH. How is maternal nutrition related to preterm birth? 2011;31:235-61.

8. Roseboom TJ, Painter RC, van Abeelen AF, Veenendaal MV, de Rooij SRJM. Hungry in the womb: what are the consequences? Lessons from the Dutch famine. 2011;70(2):141-5.

9. Aloosh M, Salavati A, Aloosh AJPh. Economic sanctions threaten population health: the case of Iran. 2019;169:10-3.

10. Kokabisaghi F. Assessment of the Effects of Economic Sanctions on Iranians' Right to Health by Using Human Rights Impact Assessment Tool: A Systematic Review. International journal of health policy and management. 2018;7(5):374-93.

11. Danaei G, Harirchi I, Sajadi HS, Yahyaei F, Majdzadeh R. The harsh effects of sanctions on Iranian health. The Lancet. 2019;394(10197):468-9.

12. Verbeke G. Models for Discrete Longitudinal Data: Springer January 28, 2006.

13. Liang KY, Zeger SL, Qaqish BJJotRSSSB. Multivariate regression analyses for categorical data. 1992;54(1):3-24.

14. Zeger SL, Liang KYJSim. An overview of methods for the analysis of longitudinal data. 1992;11(1415):1825-39.

15. Hufbauer GC, Schott JJ, Elliott KA. Economic sanctions reconsidered: History and current policy: Peterson Institute; 1990.

16. Moret ESJES. Humanitarian impacts of economic sanctions on Iran and Syria. 2015;24(1):120-40.

17. Gorji A. Sanctions against Iran: The Impact on Health Services. Iranian journal of public health. 2014;43(3):381-2.

18. Massoumi RL, Koduri S. Adverse effects of political sanctions on the health care system in Iran. Journal of global health. 2015;5(2):020302.

19. Madani-Lavassani YJM, Conflict, Survival. Sanctions on Iran and their impact on child health. 2020:1-9. 
20. Khosravi M, Keshavarz S, Moshafi M. The most important factors affecting anthropometric indices in newborns of Bojnord in 2001. 2005.

21. Mulder-Sibanda MJRPdSP. Nutritional status of Haitian children, 1978-1995: Deleterious consequences of political instability and international sanctions. 1998;4:346-9.

22. Wigfield WJPh. The effect of economic recession on the growth of coventry children. 1978;92(2):768.

23. Mirzadehahari Z, Mohammadi-Nasrabadi F, Eini-Zinab H, Khosravi M, Mousavi N, Agasi M. Survey of association between major depression disorder in women and household food insecurity. Iranian Journal of Nutrition Sciences \& Food Technology. 2015;10(1):9-20.

24. Heidari k. Assessing the Impact of US Sanctions on Food Security for Iranian Households. 2018;14(3):35-52.

25. Hejazi J, Emamgholipour SJIJoHP, Management. The Effects of the Re-imposition of US Sanctions on Food Security in Iran. 2020.

26. Sangsefidi ZS, Mirzaei M, Hosseinzadeh $M$. The relation between dietary intakes and psychological disorders in Iranian adults: a population-based study. BMC psychiatry. 2020;20:1-9.

\section{Figures}

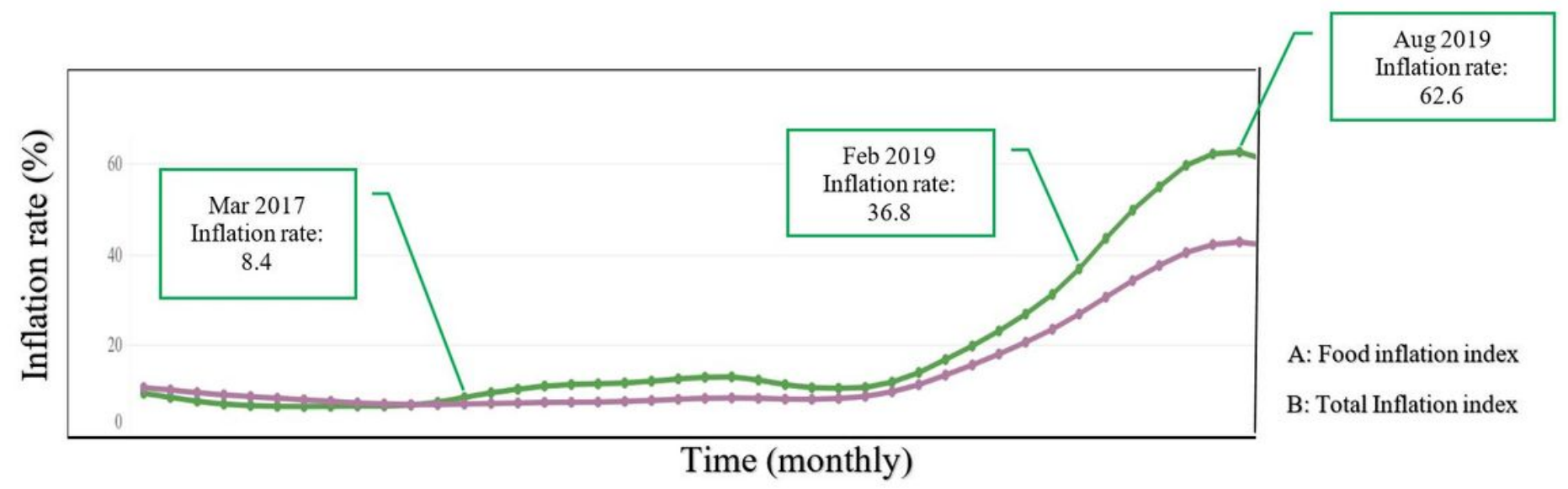

\section{Figure 1}

Status of Total Inflation Index and Food Inflation Index Based on Data of National Statistics Center of Iran (March 20, 2016-August 2019) 


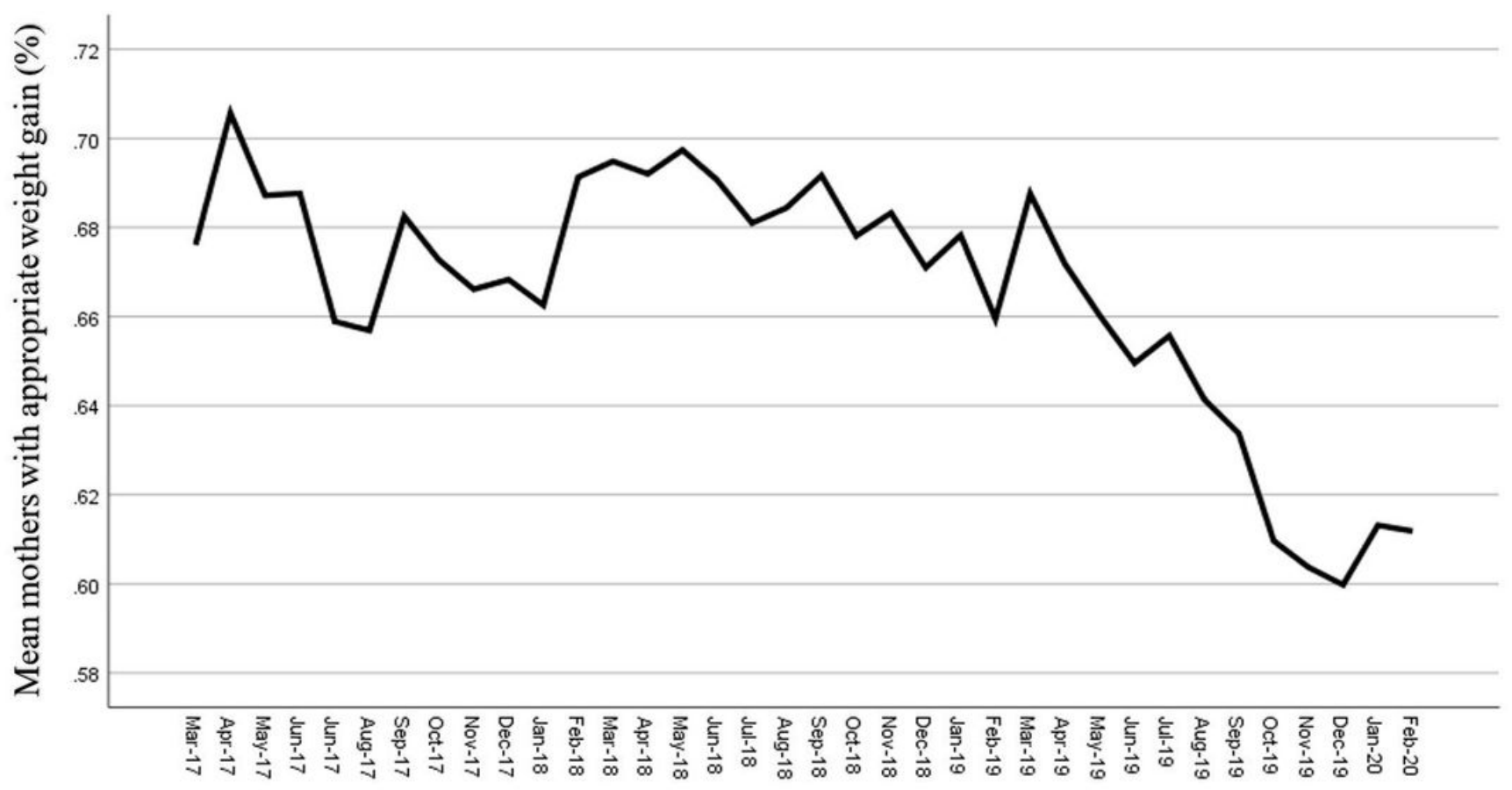

Figure 2

Trend of Weight Gain Status of Pregnant Women during 36 Months

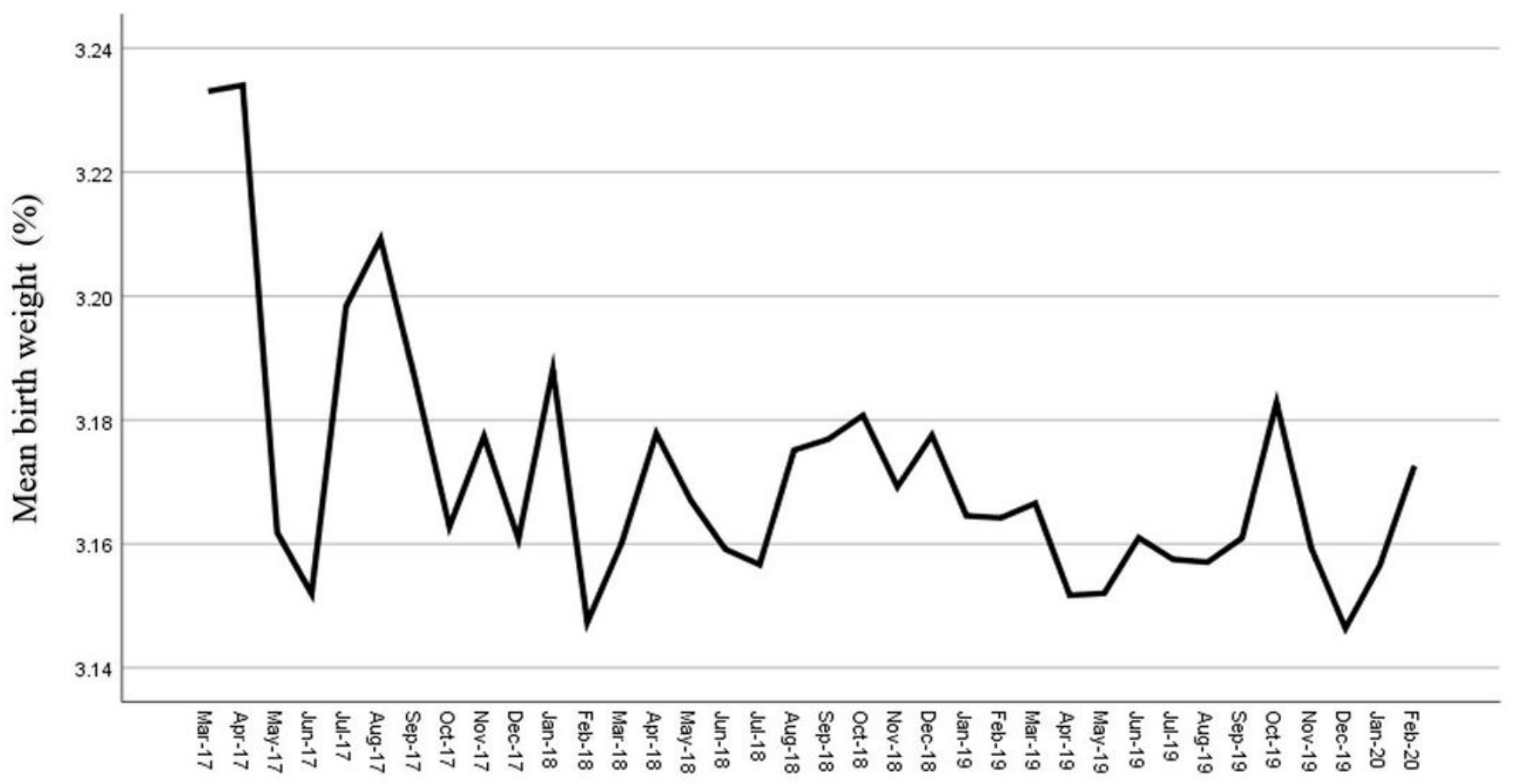

Figure 3

Trend of Birth Weight of Infants during 36 Months 
Page 12/12 